\title{
Enhanced anthraquinones production from adsorbent-treated Morinda elliptica cell suspension cultures in production medium strategy.
}

\begin{abstract}
Continuous removal of anthraquinones (AQ) by Amberlite polymeric adsorbents (XAD-4, XAD-7 and XAD-16) through in situ adsorption in Morinda elliptica cell suspension cultures is studied for product recovery and improvement of the overall titre. Ethanol was the best eluting solvent for effective recovery of AQ from all adsorbents. Pre-treatment of XAD-4 with sodium acetate not only enhanced intracellular AQ, but also AQ release and subsequent recovery from the adsorbent. The addition of sodium acetate pretreated XAD-4 on day 18 for 6-day contact period, achieved comparable cell growth to control $(41 \mathrm{~g} / \mathrm{L})$, but with 1.3 -fold higher intracellular AQ (124 mg/g DW) and two-fold increase in extracellular AQ (14.3 $\mathrm{mg} / \mathrm{L}$ ). High amount of adsorbent and longer contact period for the cultures entering stationary growth phase, stimulated AQ release and recovery but at the expense of cell growth. With 5-8.3 g XAD-4 adsorbent per litre M. elliptica culture in production (P) medium, between 60 and 90\% AQ was recovered from extracellular AQ after 24-26 days of culture period.
\end{abstract}

Keyword: Morinda elliptica, Anthraquinones, Cell culture, Amberlite polymeric adsorbent, In situ adsorption 